\title{
Rising trends of caesarean section: a retrospective study
}

\author{
Namrata Sethi, Sushma P. Sharma* \\ Department of Obstetrics and Gynecology, M. I. M. E. R. Medical College, Pune, Maharashtra, India
}

Received: 16 January 2019

Accepted: 11 February 2019

\section{*Correspondence:}

Dr. Sushma P. Sharma,

E-mail: sushmas07@gmail.com

Copyright: (c) the author(s), publisher and licensee Medip Academy. This is an open-access article distributed under the terms of the Creative Commons Attribution Non-Commercial License, which permits unrestricted non-commercial use, distribution, and reproduction in any medium, provided the original work is properly cited.

\section{ABSTRACT}

Background: The indications of Caesarean Section (CS) have been changing over time, along with a visible, much talked about rise in the rate. Without a doubt, $\mathrm{C}$-sections can effectively prevent maternal and perinatal mortality when done for a medical indication. However, little is researched about the extent of maternal indications and the fetal outcomes of C-sections.

Methods: Data of January to March 2012 and January to March 2017 was obtained by detailed study of the patient files from the Medical Records Department of the hospital. A predesigned proforma was used to record the relevant information. Data was analysed using standard statistical methods.

Results: Cephalo pelvic disproportion (CPD) and fetal distress (FD) remained the major causes of CS in both the groups, being $50.4 \%$ in group2012 and $60.5 \%$ in group2017. Trends of CS due to maternal demand and tubal ligations are emerging. Though the rise in CS was not significant in the 5 year period having gone up from $45.41 \%$ to $48.81 \%$, there was significant increase in deliveries without complications, having jumped up from $74.8 \%$ to $88.3 \%$.

Conclusions: As per the study, there was non-significant rise in the incidence of $\mathrm{C}$-sections in the time period of study. Major contributory factors observed were CPD and FD, in which it is imperative to perform C-sections.

Keywords: Caesarean section, Cephalo pelvic disproportion, Fetal distress, Maternal demand, Rising trend, Tubal ligation

\section{INTRODUCTION}

The name "Caesarean Section" is believed to be derived from Julius Caesar's birth, which was surgical. The indications of Caesarean Section (CS/ C-sections) have been changing over time. Earlier, it was performed as a means of saving the baby's life. Later, maternal distress also got added to the indications.

The operation started to be performed as a routine procedure, with growth of hospitals and increased urbanisation. ${ }^{1}$ Ever since 1985, the ideal rate for Cesarean sections has been considered to be $10-15 \%$ by the international healthcare community. ${ }^{2}$ According to a research article, the global average CS rate increased from $6.7 \%$ to $19.1 \%$ between 1990 and $2014 .^{3}$

According to The Federation of Obstetric and Gynecological Societies of India, "the hallmark of labor management in the $21^{\text {st }}$ century should be individualized care for the laboring woman with the expectation of a successful and safe vaginal delivery, together with the ability to intervene with a cesarean delivery, if needed, to prevent morbidity and mortality". ${ }^{4}$

Without a doubt, C-sections can effectively prevent maternal and perinatal mortality when done for a medical indication. However, little is researched about the extent 
of maternal indications and the fetal outcomes of Csections.

The primary aim was to study the incidence of $\mathrm{C}$-section in a rural medical college hospital and compare the data in January to March 2017 with that of 5 years ago (January to March 2012).

The secondary aims were to study the indications for the C-sections; to study the fetal outcome of C-sections; to study the morbidity in patients who have undergone Csections, and to evaluate the rate of tubal ligation associated with the $\mathrm{C}$-Sections in the included time period.

\section{METHODS}

This was an observational type of study. After ethical clearance, data was collected by analyzing file records.

\section{Inclusion criteria}

- All females undergoing C-sections (elective and emergency) from January 2012 to March 2012 and from January 2017 to March 2017.

\section{Exclusion criteria}

- Full term vaginal delivery,
- Forceps use,

- Vacuum use.

Data of January to March 2012 and January to March 2017 was obtained by detailed study of the patient files from the Medical Records Department of the hospital. A predesigned proforma was used to record relevant information, which included the age of the patient, past obstetric history, indication for the C-section being performed, whether tubal ligation was performed along with the $\mathrm{C}$-section in question, maternal outcome in terms of complications, and also neonatal outcomes like birth weight, NICU admission and mortality.

\section{Statistical analysis}

Collated data was analysed using standard statistical methods, which included the $\mathrm{Z}$ test for two proportions (using the confidence level of $95 \%$ ).

\section{RESULTS}

Following are the observations for January to March 2012 as well as January to March 2017-referred to as "group 2012" and "group 2017" respectively.

Rate of C-section in group 2012 was $119 / 262=45.41 \%$ and in group 2017 was $205 / 420=48.81 \%$ as may be observed from Table 1.

Table 1: Incidence of CS.

\begin{tabular}{|l|l|l|l|}
\hline Group & Total number of deliveries & C-sections & \% of C-section out of total deliveries \\
\hline 2012 & 262 & 119 & 45.41 \\
\hline 2017 & 420 & 205 & 48.81 \\
\hline
\end{tabular}

As indicated in Table 2, the maternal age range for group 2012 is 19-30 years and for group 2017 is 18-36 years. The mean age for group 2012 is 23.28 years and for group 2017 is 23.87 years.

Table 2: Maternal age.

\begin{tabular}{|l|l|l|l|} 
Group & $\begin{array}{l}\text { Number of } \\
\text { women undergoing } \\
\text { C-section }\end{array}$ & $\begin{array}{l}\text { Age } \\
\text { range } \\
\text { (years) }\end{array}$ & $\begin{array}{l}\text { Mean } \\
\text { age } \\
\text { (years) }\end{array}$ \\
\hline 2012 & 119 & $19-30$ & 23.28 \\
\hline 2017 & 205 & $18-36$ & 23.87 \\
\hline
\end{tabular}

The parities of the women in group 2012 and group 2017 were compared in the categories of: primiparous, multiparous, grand multiparous.

As depicted in Figure 1 and 2, group 2012 had 69 primiparous, 50 multiparous and 0 grand multiparous women out of 119. On the other hand, group 2017 had
118 primiparous, 86 multiparous women and 1 grand multiparous woman out of 205.

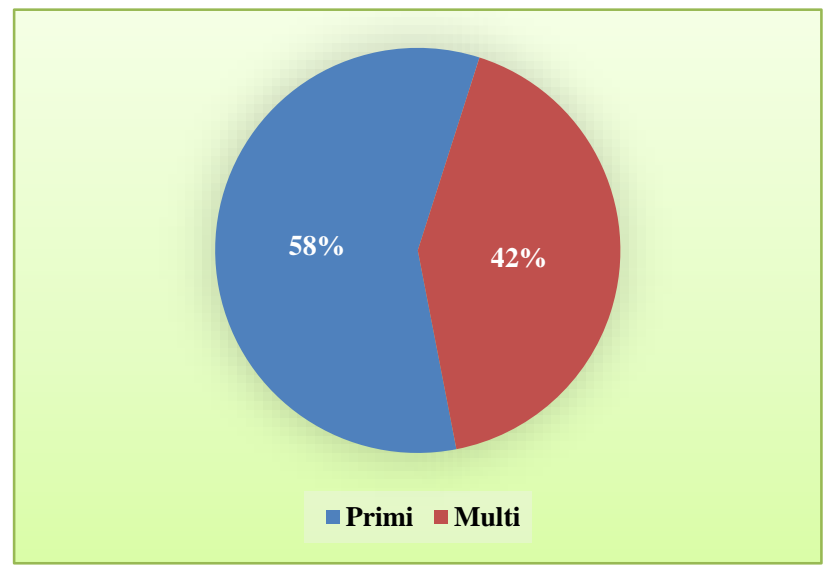

Figure 1: Parity of women undergoing C-sectionJanuary to March 2012. 


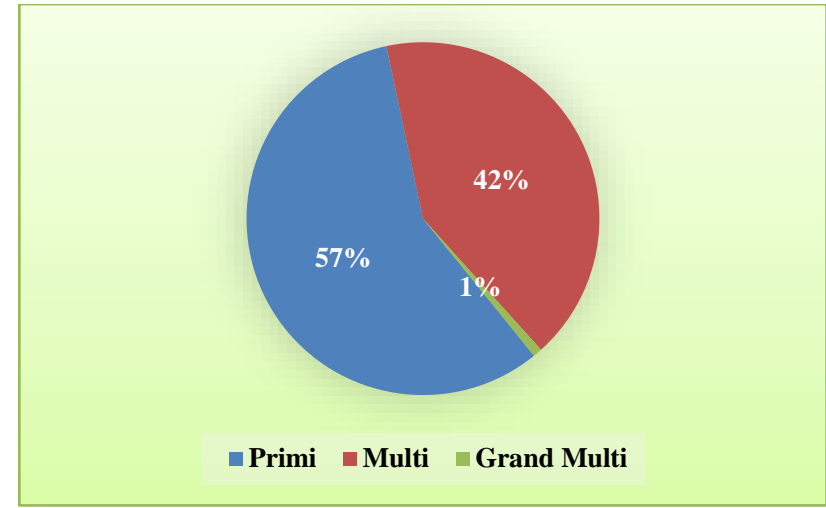

Figure 2: Parity of women undergoing C-sectionJanuary to March 2017.

Number of living children of women undergoing the Csections in the inclusion period were observed as shown in Figure 3 (no. of women expressed as percentage).

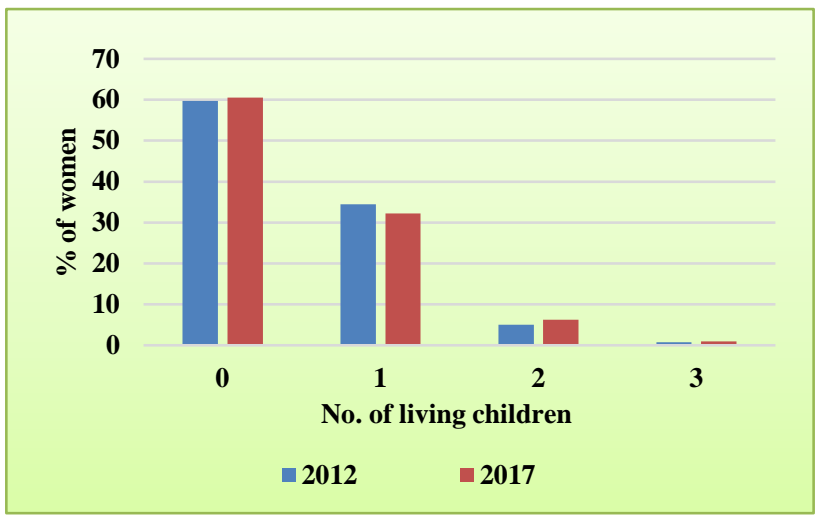

Figure 3: Number of living children of women undergoing $\mathrm{C}$-section in both groups.

Gestational age at the time of LSCS was observed. Completed weeks were considered. The number of women in the inclusion period to have undergone LSCS at particular weeks was recorded. As mentioned in Table 3 , the range in group 2012 was found to be 33-42 weeks whereas the range in group 2017 was $33-41$ weeks. The mean gestational age in case of group 2012 turned out to be 38.34 weeks (38W2D), similar to 38.24 weeks (38W2D) in group 2017.

Table 3: Gestational age of women undergoing Csection in both groups.

\begin{tabular}{|l|l|l|}
\hline Group & Gestational age range in weeks & Mean \\
\hline 2012 & $33-42$ & $38 \mathrm{~W} 2 \mathrm{D}$ \\
\hline 2017 & $33-41$ & $38 \mathrm{~W} 2 \mathrm{D}$ \\
\hline
\end{tabular}

The percentage of C-sections out of total i.e. 119 in group 2012 and 205 in group 2017 to be taking place for each indication is given in Table 4.
Table 4: Indications for the $\mathrm{C}$-sections that were performed in the period of study.

\begin{tabular}{|l|l|l|}
\hline Group & 2012 (in \%) & 2017 (in \%) \\
\hline Breech & 9.2 & 2.9 \\
\hline CPD $^{\mathrm{a}}$ & 29.4 & 30.7 \\
\hline Eclampsia & 5.9 & 2.0 \\
\hline DTA $^{\mathrm{b}}$ & 1.7 & 0 \\
\hline MSL $^{\mathrm{c}}$ & 5.9 & 8.2 \\
\hline Fetal distress & 21.0 & 29.8 \\
\hline Non-progress of labour & 5.9 & 5.8 \\
\hline Abruption & 1.7 & 0 \\
\hline Previous 2 LSCS & 4.2 & 2.0 \\
\hline Previous 1 LSCS & 10.9 & 14.1 \\
\hline Transverse Lie & 4.2 & 2.0 \\
\hline Direct OP & 0 & 0.5 \\
\hline LOT $^{\mathrm{e}}$ & 0 & 0.5 \\
\hline Patient's desire & 0 & 1.5 \\
\hline
\end{tabular}

${ }^{a} \mathrm{CPD}=$ Cephalo Pelvic Disproportion, ${ }^{\mathrm{b}} \mathrm{DTA}=$ Deep Transverse Arrest, ${ }^{\mathrm{c} M S L}=$ Meconium Stained Liquor, ${ }^{\mathrm{d}} \mathrm{OP}=$ Occipito Posterior, ${ }^{\mathrm{e}} \mathrm{LOT}=\mathrm{Left}$ Occiput Transverse

The rate of tubal ligation associated with $\mathrm{C}$-section deliveries in group 2012 was $3 / 119=2.5 \%$ and in group 2017 was $24 / 205=11.7 \%$.

Maternal outcome associated with $\mathrm{C}$-sections was recorded in terms of intra-operative surgical complications (intraabdominal adhesions, bleeding from placental sinuses, couvelaire uterus, retroplacental clot, fibroid), wound complications (gaping with or without discharge), infection (urinary tract or respiratory tract), fever, puerperal complications ( $\mathrm{PPH}$, mastitis, uterine subinvolution). Percentages of women with these outcomes have been recorded in Table 5 .

Table 5: Complications of the $\mathrm{C}$-sections that were performed in the period of study.

\begin{tabular}{|l|l|l|}
\hline Group & $2012(\mathrm{in} \%)$ & 2017 (in \%) \\
\hline No complication & 74.8 & 88.3 \\
\hline $\begin{array}{l}\text { Intraoperative surgical } \\
\text { complication }\end{array}$ & 10.1 & 2.0 \\
\hline Wound complication & 10.9 & 2.4 \\
\hline UTI/RTI & 2.5 & 4.9 \\
\hline Fever & 0 & 1 \\
\hline Puerperal complication & 1.7 & 1.4 \\
\hline
\end{tabular}

Fetal outcome was recorded in terms of birth weight and rate of NICU admission, as displayed in Table 6. Reasons observed for NICU admissions were amongst: observation, evaluation, large for gestational age, respiratory distress, low birthweight, Rh incompatibility, TORCH infection, lateral ventricular dilatation. In group 2012 , there were 2 stillbirths in the category $2.5-3 \mathrm{~kg}$, and 2 children expired in NICU, 1 in category $<2.5 \mathrm{~kg}$ and 1 in $2.5-3 \mathrm{~kg}$. In group 2017, there was 1 stillbirth in the category $2.5-3 \mathrm{~kg}$. 
Table 6: NICU data on weight and number of babies born from the C-sections in the period of study.

\begin{tabular}{|l|l|l|l|l|}
\begin{tabular}{|l|l|l|} 
Weight \\
in $\mathrm{kg}$
\end{tabular} & $\begin{array}{l}\text { Number of } \\
\text { newborns }\end{array}$ & $\begin{array}{l}\text { \% of newborns having weight in } \\
\text { that particular range }\end{array}$ & $\begin{array}{l}\text { Newborns } \\
\text { in NICU }\end{array}$ & $\begin{array}{l}\text { \% of newborns } \\
\text { in NICU }\end{array}$ \\
\hline & 13 & 10.8 & 13 & 100 \\
\hline$<2$ & 22 & 18.3 & 19 & 86 \\
\hline $2-2.5$ & 57 & 47.5 & 19 & 33 \\
\hline $2.5-3$ & 23.3 & 11 & 39 \\
\hline $3-3.5$ & 28 & 0 & 0 & 0 \\
\hline $3.5-4$ & 0 & 100 & 62 & 52 \\
\hline Total & 120 & & & \\
\hline & & 3.4 & 5 & 71 \\
\hline$<2$ & 7 & 19.8 & 13 & 32 \\
\hline $2-2.5$ & 41 & 47.8 & 20 & 20 \\
\hline $2.5-3$ & 99 & 23.7 & 12 & 25 \\
\hline $3-3.5$ & 49 & 5.3 & 3 & 27 \\
\hline $3.5-4$ & 11 & 100 & 53 & 26 \\
\hline Total & 207 & & & \\
\hline
\end{tabular}

The total number of newborns was observed to be higher than the total number of C-sections in both groups 2012 and 2017 because of birth of twins (1 case in group 2012 and 2 cases in group 2017) as may be noticed from Table 6.

\section{DISCUSSION}

According to National Family Health Survey 4 (20142015), the rate of CS in rural Maharashtra is $53.4 \%$. The incidence of $\mathrm{C}$-sections in present study was $45.41 \%$ in group 2012 and $48.81 \%$ in group 2017 . Thus, this sample is a representation of the population of rural Maharashtra. However, by the $\mathrm{Z}$ test for two proportions, the rise within the span of 5 years is not significant $(Z=0.87)$.

There is no change in mean age (23 years) of women undergoing CS. In group 2012, majority of the C-section cases $(98 \%)$ were up to the age of 28 years and maximum age observed was 30 years. However, in group 2017, $89 \%$ cases were up to the age of 28 and maximum age observed was 36 years.

The percentage of women undergoing $\mathrm{C}$-sections for their first deliveries vis-à-vis multi remained the same at $58 \%$, in both groups. Majority of women (about 60\%) in both groups undergoing $\mathrm{C}$-section were primigravidae, or multigravidae with bad obstetric history (spontaneous abortions/stillbirths/expired children). Hence, majority of women undergoing $\mathrm{C}$ section had no previous living children. Another point to be noted is that the incidence of C-sections steadily decreased as the number of living children increased.

The mean age of gestation for C-section in both groups is 38 weeks 2 days. The definition of full term and post term pregnancy has remained the same through these years, which could be why the mean gestational age for both groups has turned out to be the same. While $25 \%$ of the cases fell under $38 \mathrm{w}$ completed gestational age in group 2012, $36 \%$ of the cases were under the same category in group 2017.

Number of cesarean deliveries due to breech went down from $9.2 \%$ in group 2012 to $2.9 \%$ in group2017. This is a significant fall ( $\mathrm{Z}$ test for two proportions=2.17). Cephalo pelvic disproportion and fetal distress remained the major causes of caesarean deliveries in both groups. They accounted for 50\% C-sections in group 2012 and $60 \%$ in group 2017. Fetal distress was found to be the largest contributor to primary cesarean delivery as per other studies. $^{5,6}$

Previous LSCS was the third most common indication in both the groups in this study. In a study conducted in Gujarat, previous LSCS turned out to be the most common indication, fetal distress, breech and prolonged labour following it. ${ }^{7}$ In another study in Rajasthan, the most common indication was previous LSCS. ${ }^{8}$ The same result was seen in other studies conducted in Eastern and Southern India. ${ }^{9,10}$ This trend is seen to be beginning in present study in rural Maharashtra as well, although it is not significant at present.

Patient's desire as an indication has appeared in the second group. This particular trend has been observed in a study conducted in Connecticut, wherein indications exhibiting large annual percentage increases included maternal request. ${ }^{6}$

Rate of C-sections due to previous 1 LSCS has increased from $10.9 \%$ to $14.1 \%$ (non-significant rise, $Z=0.85$ ). However, a significant increase in the repeat caesarean rate among all live births was found in another study. ${ }^{6}$ The trend of tubal ligation along with $\mathrm{C}$-section has become more popular in the span of 5 years: $2.5 \%$ in 
group 2012 to $11.7 \%$ in group 2017, which is quite significant $(\mathrm{Z}=3.46)$.

The number of cases of C-sections without any associated complications has gone up from $74.8 \%$ to $88.3 \%$ (significant improvement- $\mathrm{Z}=2.95$ ). There has been a decrease in intraoperative as well as wound complications. Infections (RTI, UTI) post operatively have gone up, although the rise is not significant $(\mathrm{Z}=1.15)$.

In a different study however, the commonest complication was wound infection (similar to group 2012 in present study) followed by UTI (most common complication in group 2017 in present study). ${ }^{10}$

In group 2012, overall $51.67 \%$ of newborns had to be admitted to the NICU whereas in group 2017, the percentage went down to $25.6 \%$. This is a significant decrease $(Z=4.76)$, which indicates a generalized improvement in neonatal outcome over the years.

A large majority of neonates being admitted to the NICU was underweight $(<2 \mathrm{~kg})$ in both groups. However, the percentage of newborns in the weight category 3.5 to $4 \mathrm{~kg}$ went up from $0 \%$ in group 2012 to $5.3 \%$ in group 2017 ( $\mathrm{Z}$ test of two proportions $=3.42$, meaning this is a significant rise). This could be due to better ante-natal care and nutrition, as well as a rise in incidence of gestational diabetes mellitus.

\section{CONCLUSION}

There is a general notion of an alarming rise in the rate of cesarean sections in the past few years This study was carried out to analyse the truth in that notion, with the help of appropriate statistical tools. The aim of this study was to evaluate the different trends associated with $\mathrm{C}$ Sections, and how they have changed in the past 5 years.

As per the analysis, there has been a statistically nonsignificant rise in the incidence of $\mathrm{C}$-sections in the time period of study. That being said, multiple factors play a role in determining the rate of $\mathrm{C}$-sections. Major contributing factors in present study have been cephalo pelvic disproportion and fetal distress, in which it is imperative to perform a C-section. Therefore, the question of appropriation does not arise.

Other indications like non progress of labour, and previous 1 LSCS, need to be looked into, and may be decreased by proper obstetric audit. This being a study conducted on a limited population, a multicentric population and meta-analysis of various cesarean sections is required.

Funding: No funding sources

Conflict of interest: None declared

Ethical approval: The study was approved by the Institutional Ethics Committee

\section{REFERENCES}

1. Cesarean section-a brief history. Available at: https://www.nlm.nih.gov/exhibition/cesarean/.

2. WHO statement on caesarean section rates. Available at: https://www.who.int/reproductivehealth/publications /maternal_perinatal_health/cs-statement/en/.

3. Betrán AP, Ye J, Moller AB, Zhang J, Gülmezoglu $\mathrm{AM}$, Torloni MR. The increasing trend in caesarean section rates: global, regional and national estimates: 1990-2014. PloS One. 2016;11(2):e0148343.

4. FOGSI-Cesarean Rates (JDT). Available at: https://www.fogsi.org/fogsi-cesarean-rates-jdt/.

5. Mittal S, Pardeshi S, Mayadeo N, Mane J. Trends in Cesarean Delivery: Rate and Indications. J Obstet Gynaecol India. 2014;64(4):251-4.

6. Barber EL, Lundsberg L, Belanger K, Pettker CM, Funai EF, Illuzzi JL. Contributing indications to the rising cesarean delivery rate. Obstet Gynecol. 2011;118(1):29.

7. Desai G, Anand A, Modi D, Shah S, Shah K, Shah $\mathrm{A}$, et al. Rates, indications, and outcomes of caesarean section deliveries: A comparison of tribal and non-tribal women in Gujarat, India. PLoS One. 2017;12(12):e0189260.

8. Verma S, Saini J, Sehra R, Nagaraj N. A clinical study of rate and indications of cesarean section, maternal and fetal outcomes at tertiary care center in north western Rajasthan. Int J Reprod Contracept Obstet Gynecol. 2016;5:2791-4.

9. Das RK, Subudhi KT, Mohanty RK. The rate and indication of caesarean section in a tertiary care teaching hospital eastern India. Int J Contemp Pediatr. 2018;5:1733-9

10. Santhanalakshmi C, Gnanasekaran V, Chakravarthy AR. A retrospective analysis of cesarean section in a tertiary care hospital. Int J Sci Res. 2013;4(9):20979 .

Cite this article as: Sethi N, Sharma SP. Rising trends of caesarean section: a retrospective study. Int J Reprod Contracept Obstet Gynecol 2019;8:154852. 